\title{
16 hospitalizations daily for opioid poisoning
}

\author{
Cite as: CMAJ 2017 October 2;189:E1248. doi: 10.1503/cmaj.1095503
}

Posted on cmajnews.com on Sept. 14, 2017.

$\mathbf{T}$ he rate of people admitted to hospital for opioid poisoning has increased $53 \%$ over the past decade, according to the report "Hospitalizations and Emergency Department Visits Due to Opioid Poisoning in Canada" by the Canadian Institute for Health Information.

On average, 16 Canadians are hospitalized for this problem every day. In 2016-17, more than half of these incidents were considered accidental and a third the result of self-inflicted harm.
Emergency departments across the country are seeing a large increase in patients with opioid poisoning. Departments in Alberta and Ontario both saw increases of about 50\% between 2012-13 and 2016-17. Visits for poisoning with heroin and synthetic opioids are both on the rise.

Overall, the hospitalization rate for opioid poisoning in Canada is 15.6 per 100000 people. There were about 5670 hospitalizations in total in 2016-17.

Rates are higher in Western Canada (25 per 100000 in British Columbia, 23.1 in
Alberta and 21.7 in Saskatchewan) than in Eastern and Central Canada. The rate is estimated to be even higher in Yukon, Northwest Territories and Nunavut, but the data are insufficient and should be "interpreted with caution."

Seniors and Canadians age 45-64 have the highest rates of hospitalization for opioid poisoning, but rates are increasing the most in younger adults and youth age $15-24$.

\section{Roger Collier, CMAJ}

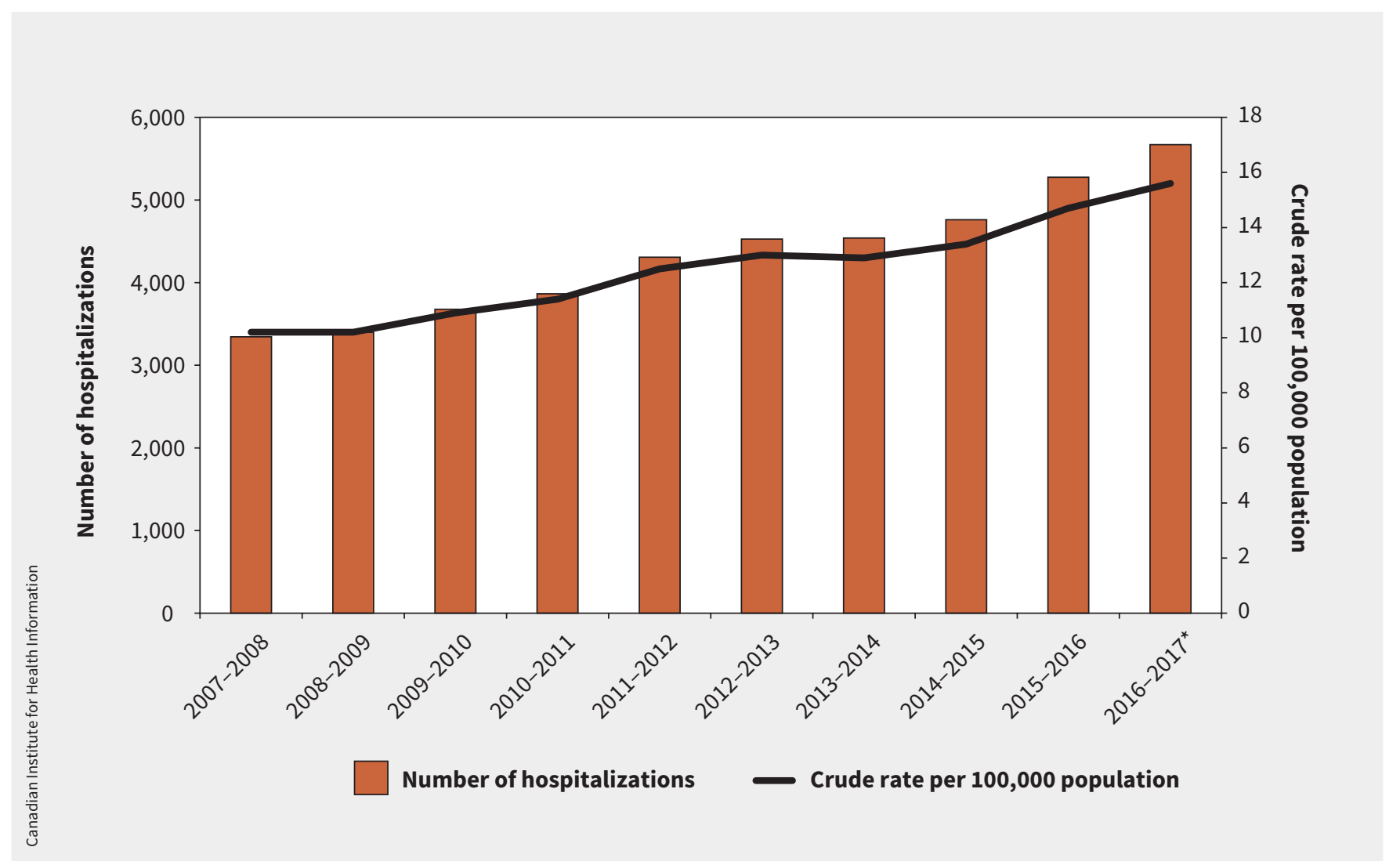

The hospitalization rate for opioid poisoning increased $53 \%$ over past decade. 